\title{
A Dicer-like protein in Tetrahymena has distinct functions in genome rearrangement, chromosome segregation, and meiotic prophase
}

\author{
Kazufumi Mochizuki and Martin A. Gorovsky ${ }^{1}$ \\ Department of Biology, University of Rochester, Rochester, New York 14627, USA
}

\begin{abstract}
Previous studies indicated that genome rearrangement involving DNA sequence elimination that occurs at late stages of conjugation in Tetrahymena is epigenetically controlled by siRNA-like scan (scn) RNAs produced from nongenic, heterogeneous, bidirectional, micronuclear transcripts synthesized at early stages of conjugation. Here, we show that Dcl1p, one of three Tetrahymena Dicer-like enzymes, is required for processing the micronuclear transcripts to scnRNAs. DCL1 is also required for methylation of histone $\mathrm{H} 3$ at Lys 9, which, in wild-type cells, specifically occurs on the sequences (IESs) being eliminated. These results argue that Dcl1p processes nongenic micronuclear transcripts to scnRNAs and is required for IES elimination. This is the first evidence linking nongenic micronuclear transcripts, scnRNAs, and genome rearrangement. Dcl1p also is required for proper mitotic and meiotic segregation of micronuclear chromosomes and for normal chromosome alignment in meiotic prophase, suggesting that DCL1 has multiple functions in regulating chromosome dynamics.
\end{abstract}

[Keywords: Tetrahymena; RNAi; dicer; genome rearrangement; centromere]

Supplemental material is available at http://www.genesdev.org.

Received September 23, 2004; revised version accepted November 5, 2004.

Nuclear dimorphism is one of the most striking features of ciliated protozoa, including Tetrahymena thermophila (referred to as Tetrahymena). Each interphase Tetrahymena cell has a macronucleus (Mac) and a micronucleus (Mic). The Mac is polyploid and is transcriptionally active, while the Mic is diploid and is transcriptionally inert in vegetative cells. The Mic divides mitotically. In contrast, the Mac divides amitotically, and Mac chromosomes are randomly assorted, not segregated, when it divides (Prescott 1994). This difference probably reflects the presence of centromeres in Mics and their absence in Macs.

The Mic undergoes meiosis during the sexual process of conjugation to form two haploid pronuclei, one of which is reciprocally exchanged between the two conjugating cells. The migratory and stationary pronuclei then fuse to create a zygotic nucleus that divides to produce the next generation of new Macs and Mics. After the new Mac forms, the old, parental Mac is destroyed. During development of the new Mac, massive rearrangement and endoreplication of the genome occurs (Jahn and Klobutcher 2002; Yao et al. 2002); 15\% of the Mic genome is eliminated during genome rearrangement. Two

${ }^{1}$ Corresponding author.

E-MAIL goro@mail.rochester.edu; FAX (585) 275-2070.

Article published online ahead of print. Article and publication date are at http://www.genesdev.org/cgi/doi/10.1101/gad.1265105. types of eliminated sequences have been identified. Breakage-eliminated sequences (BES) consist of relatively short ( $<50 \mathrm{bp}$ ) regions that flank a conserved, $15-\mathrm{bp}$ chromosome breakage sequence (Cbs). These breakage sites are healed by addition of telomeres at the end of the Mac-destined sequences (MDSs). The second type, internal eliminated sequences (IES), range in size from $\sim 0.5$ to $20 \mathrm{~kb}$, and are mostly moderately repeated in the Mic. IES elimination sites are healed by religation of flanking MDSs. Although IESs are flanked by short (1 to $\sim 10 \mathrm{bp}$ ) direct repeats, the sequences of these repeats vary in different IESs, and no consensus sequences have been found in or around IESs that explain how they are targeted for elimination.

An RNAi-related mechanism is involved in IES elimination. Twilp, a member of the PPD (PAZ-Piwi domain)/ Argonaute protein family involved in RNAi-related processes, is required for IES elimination (Mochizuki et al. 2002; Mochizuki and Gorovsky 2004a). siRNA-like 28nucleotide (nt) scan RNAs (scnRNAs) are specifically expressed during conjugation (Mochizuki et al. 2002). Twilp is complexed with scnRNAs and is required for their accumulation (Mochizuki et al. 2002, Mochizuki and Gorovsky 2004a). The specificity of scnRNAs for Mic-limited sequences gradually increases during conjugation (Mochizuki and Gorovsky 2004a). Also, injection of dsRNAs homologous to MDSs induces elimination of the MDSs during conjugation (Yao et al. 2003). 
We proposed a model to explain how IESs are recognized during Mac development by an RNAi-related mechanism (Mochizuki et al. 2002, Mochizuki and Gorovsky 2004b). In the model, the Mic genome is transcribed bidirectionally to make double-stranded RNAs (dsRNAs) that are processed to scnRNAs in the cytoplasm. There, scnRNAs complex with Twilp and are transferred to the old Mac, where the scnRNAs homologous to Mac DNA sequences are degraded. We hypothesized that the remaining Mic-specific scnRNAs, still complexed with Twilp, are then transferred to the new $\mathrm{Mac}$, where they promote elimination of the IES sequences to which they are homologous.

Although the Mic is transcriptionally inert during vegetative growth, transcription has been detected autoradiographically mainly in the elongate, crescent-shaped meiotic Mic during meiotic prophase (Sugai and Hiwatashi 1974; Martindale et al. 1985), when scnRNAs start appearing. This "crescent transcription" probably produces nongenic, heterogeneous transcripts homologous to both strands of IESs (Chalker and Yao 2001) and these "nongenic Mic transcripts" are the likely precursors of scnRNAs. However no direct evidence links crescent transcription, nongenic Mic transcripts, scnRNAs, and genome rearrangement.

RNAi-related mechanisms involve dsRNA processing, catalyzed by the RNase III ortholog Dicer /Carmell and Hannon 2004). Here, we show that a putative Dicer-like protein, Dcllp, is required for processing nongenic Mic transcripts to scnRNAs and for IES elimination. Dcllp also is required for the proper segregation of Mic chromosomes during mitosis and meiosis and for the formation of the crescent-shaped Mic, in which meiotic chromosome pairing occurs. Thus, distinct, RNAi-related pathways utilizing Dcllp are required for genome rearrangement, Mic chromosome segregation, and meiotic pairing in Tetrahymena.

\section{Results}

\section{Tetrahymena has three dicer-like genes}

We identified three genes homologous to Schizosaccharomyces pombe Dcrl (Provost et al. 2002) in the Tetrahymena genome database. cDNAs for each gene were sequenced. Schematic drawings of these proteins are shown in Figure 1A. Like most Dicer-like proteins, two of them, Dcrlp and Dcr2p, have an N-terminal RNA helicase domain and two RNase III domains near their C termini. The third, Dcllp, also has two RNase III domains near the $\mathrm{C}$ terminus, but lacks a helicase domain. Although the domain composition of Dcllp is similar to Drosha-like proteins (Fig. 1A), its RNase III domains are more related to Dicer-like proteins than to other RNase III proteins (Supplementary Fig. S1). All three Dicer-like proteins lack an obvious PAZ domain found in some Dicer-like proteins (Carmell and Hannon 2004)

To elucidate the Dicer-like protein(s) involved in the processing of nongenic Mic transcripts to scnRNAs, expression of these three genes was analyzed (Fig. 1B). DCR1 mRNA was detected in log-phase growing cells, to

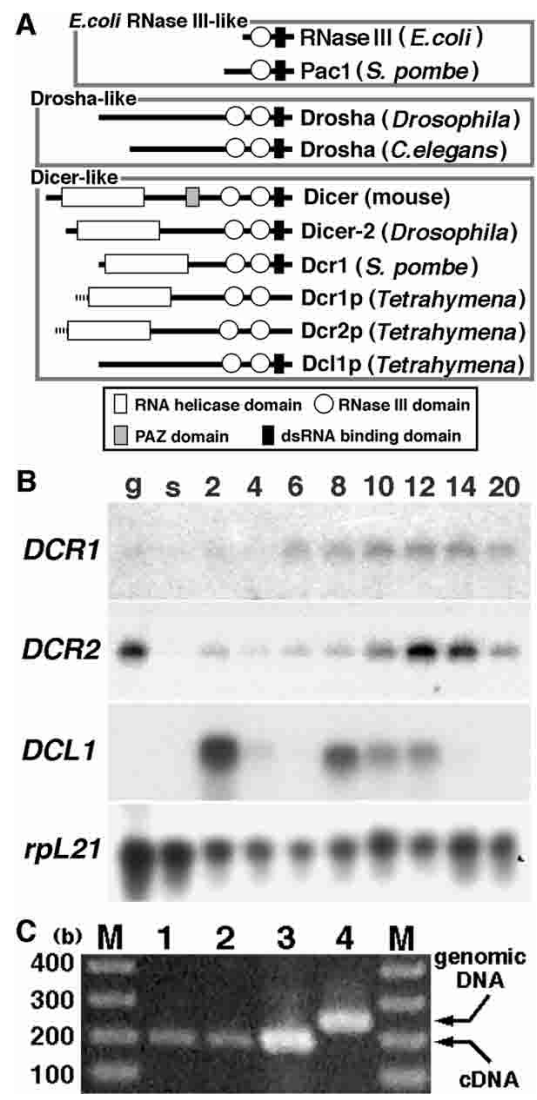

Figure 1. Characterization of dicer-related genes. (A) Comparison of RNase III enzymes. Three classes of RNase III proteins, Escherichia coli RNase III-like, Drosha-like, and Dicer-like are schematically drawn. $\mathrm{N}$ termini of Dcrlp and Dcr2p (dotted lines) have not been determined experimentally. $(B)$ mRNA expression of dicer-related genes analyzed on Northern blot. (g) Log-phase growing cells; (s) starved cells; (2-20) conjugating cells (numbers indicate hours post-mixing). Gene-specific probes were used for hybridization. Hybridization to a probe for $r p L 21$, encoding a ribosomal protein was used as a loading control. $(C)$ DCL1 mRNA is expressed in vegetative cells. Total RNA extracted from log-phase growing wild-type B2086 (lane 1), CU428 (lane 2), and mating B2086 and CU428 cells at $3 \mathrm{~h}$ post-mixing (lane 3) were used for RT-PCR. (Lane 4) Total genomic DNA of CU428 was also used for PCR. A 55-b intron is present in the genomic region, enabling the PCR products from genomic DNA (246 b) and cDNA (191 b) to be distinguished.

a lesser extent in starved and early conjugating cells, and at relatively high levels at late stages of conjugation. Expression of DCR2 was similar to that of DCR1, but it was more abundant in log-phase cells (Fig. 1B). In contrast, DCL1 expression was detected only during conjugation. DCL1 mRNA was strongly expressed early $(2 \mathrm{~h})$ in conjugation, was reduced at midstages $(4$ and $6 \mathrm{~h}$ postmixing), and again expressed (probably zygotically) at mid-to-late stages (8-12 h post-mixing). Because scnRNA accumulation starts at early $(2 \mathrm{~h})$ conjugation (Mochizuki et al. 2002), these results suggest that Dcllp is involved in its production. DCL1 mRNA was not detected in vegetative cells using Northern blots, but was 
observed by RT-PCR (Fig. 1C). Thus, DCL1 mRNA is also expressed in vegetative cells at a very low level.

\section{Dcl1p is localized in the meiotic Mic}

To localize Dcl1p, DCL1-HA, with an HA coding sequence inserted just before the translation termination codon (Supplementary Fig. S2A), was used to replace all Mac DCL1 loci to create the DCL1-HA strain. Complete replacement was confirmed by Southern hybridization (Supplementary Fig. S2B). Because DCL1 is required for proper Mic chromosome segregation (see below), Mic chromosome loss and small Mics are observed in the absence of the DCL1 function (see Fig. 4, below). DCL1HA cells did not show any such Mic abnormalities, indicating that DCL1-HA was functional.

In vegetative cells, low Dcllp-HA expression could be detected by Western blotting, but not by indirect immunofluorescent staining (data not shown), probably due to its low level and/or diffuse localization in the cell.

When a DCL1-HA strain was mated with wild-type, nontagged strain (Fig. 2), Dcllp-HA appeared in Mics shortly after mating was initiated (Fig. 2A). In most of the conjugating pairs, Mic staining in one cell was much brighter than the other, indicating that Dcllp-HA was transferred between conjugants and quickly localized in the Mic. Dcllp-HA was localized throughout the meiotic prophase "crescent" Mics (Fig. 2B,C), and was continuously observed in Mics during meiotic chromosome condensation (Fig. 2D) and during meiotic divisions (Fig. $2 F, G)$. In these stages, Dcllp-HA was localized in the Mics in an area that was broader than the area stained by DAPI (Fig. 2B-G), suggesting that it is in the nucleoplasm. Dcllp-HA started disappearing during the second meiotic division (Fig. 2G) and was not detectable after meiosis II was complete (Fig. 2H).

In meiotic prophase, crescent transcription occurs (Sugai and Hiwatashi 1974; Martindale et al. 1985) at about the same time nongenic Mic transcripts (Chalker and Yao 2001) and scnRNAs (Mochizuki et al. 2002) start accumulating. Thus, the timing of its appearance and its Mic location make Dcllp the likely enzyme that processes nongenic Mic transcripts into scnRNA.

\section{DCL1 is dispensable for viability}

We disrupted the DCL1 gene by replacing part of the coding sequence with a drug-resistance marker (neo3). The knockout construct (Fig. 3A) was introduced into Mics to give heterozygous knockout heterokaryon strains with Mics, in which one of the two copies of the DCL1 gene was replaced with the knockout construct by homologous recombination (Fig. 3A). Then, two heterozygous heterokaryon strains were mated, and the genotypes of the drugresistant progeny were analyzed by PCR (data not shown). If DCL1 is not essential, one-third of the drug-resistant progeny should be homozygous DCL1 knockouts, and two-thirds should be heterozygous (Fig. 3B; one-quarter of the total progeny should be wild type, but they are drugsensitive). Of 24 drug-resistant progeny analyzed, 10 and 14 were homozygous and heterozygous cells, respectively

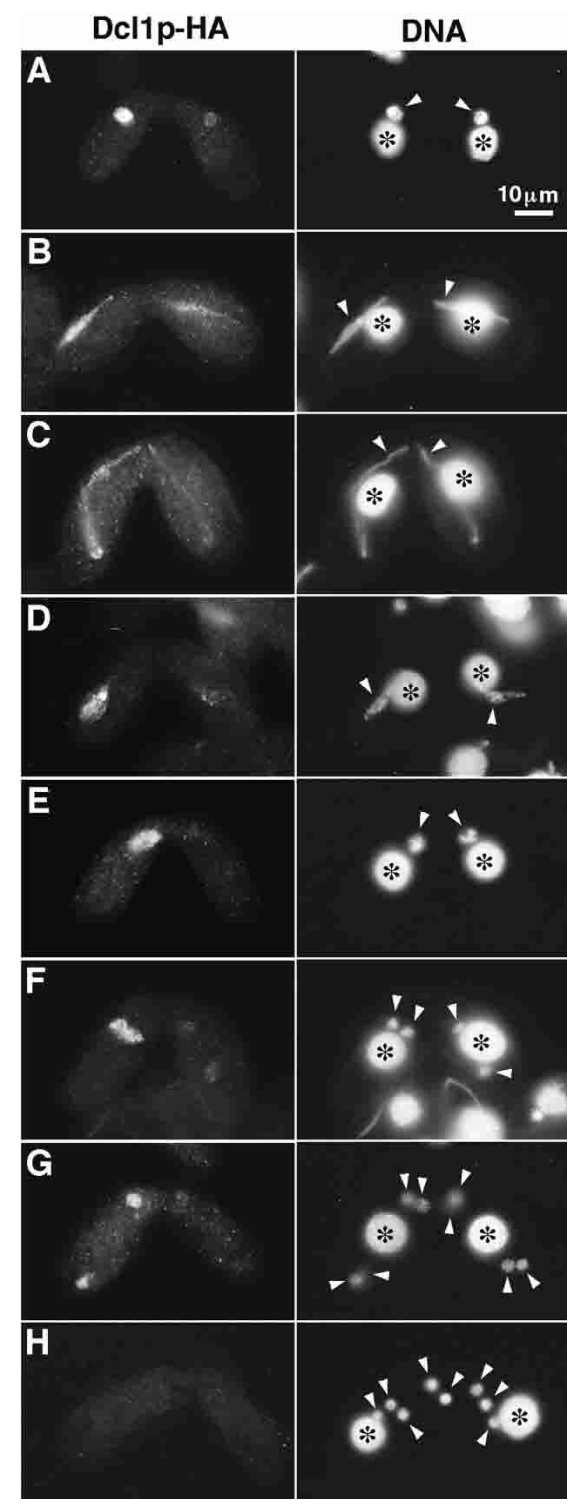

Figure 2. Localization of Dcllp-HA. The DCL1-HA strain was mated with the wild-type B2086 strain and processed for indirect immunofluorescent staining. Dcllp-HA was localized by anti-HA antibody (left) and DNA was stained with DAPI (right). Early crescent $(A)$, mid-crescent $(B)$, and late-crescent $(C)$ stages of meiotic prophase. $(D)$ Chromosome condensation. $(E, F)$ First meiosis. $(G)$ Second meiosis. $(H)$ Second meiosis completed. All photos share a common scale bar shown in $A$. Arrows and asterisks indicate Mics and Macs, respectively. For stages of mating, see Cole et al. (1997).

(Fig. 3B), indicating that zygotic expression of DCL1 in the newly formed Mac is dispensable for forming viable progeny and for vegetative growth. Two homozygous strains with complete replacement of the DCL1 loci (Fig. 3C) were used in subsequent experiments.

DCL1 is required for maintenance of Mic chromosomes during vegetative growth

Although DCL1 was not essential for vegetative growth, DCL1 knockout cells had defects in Mic chromosome 

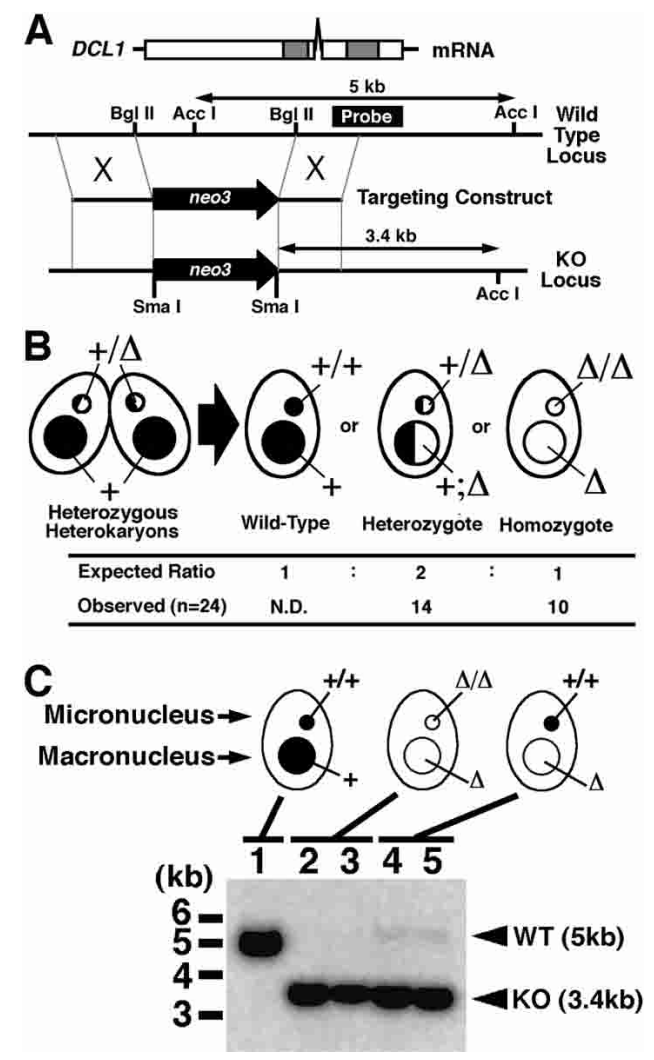

Figure 3. $D C L 1$ is not essential for vegetative growth. $(A)$ Schematic drawings of the DCL1 locus and the knockout construct used to disrupt it. The N-terminal half of the DCL1 coding sequence was replaced by the neo3 cassette that confers paromomycin resistance (pm-r) in Tetrahymena. The knockout construct was introduced into the DCL1 locus by homologous recombination. $(B)$ Viability of homozygous DCL1 KO cells. Two heterozygous DCL1 knockout heterokaryons were mated, and their progeny were selected using $\mathrm{pm}$. The genotypes of the pm-r progeny were analyzed. Of 24 pm-r progeny analyzed, 10 were homozygous. Because wild-type progeny are pm-sensitive and could not be distinguished from the parental strains, their fraction of the progeny was not determined. $(C)$ Complete replacement of endogenous DCL1 loci in the knockout strains. Total DNA isolated from wild-type CU428 (lane 1), DCL1 knockout homozygous homokaryons (lanes 2,3), and DCL1 somatic knockout strains (lanes 4,5) was digested with AccI and SmaI and the Southern blot was hybridized with the probe shown in $A$. Positions of the bands for wild-type (WT) and disrupted $(\mathrm{KO})$ loci are indicated with arrowheads. The faint, wildtype size bands observed in DCL1 somatic knockout strains were from Mics that had wild-type DCL1 loci.

maintenance. Most DCL1 knockout cells had small Mics (Fig. 4B). This defect was particularly obvious when the Mics started to elongate into the crescent shape in meiotic prophase. Although the Mics made crescents when DCL1 knockout cells were mated with wild-type cells, the amount of DNA in the Mics of the knockout cells was much lower than that of the wild-type cells (Fig. $4 \mathrm{C}, \mathrm{D}$ ), suggesting that $D C L 1$ is required for maintenance of Mic chromosomes during vegetative growth.

There are two possible explanations of the require- ment for DCL1 for Mic chromosome maintenance in vegetative cells. The first is that a low level of expression of DCL1 in vegetative cells (Fig. 1C) is required for Mic chromosome maintenance. Alternatively, it is possible that zygotically expressed DCL1 at late conjugation stages (at 8-12 h post-mixing) (Fig. 1B) was required for differentiation of the Mic. In this latter, "bad Mic" hypothesis, the Mic acquires defects in chromosome maintenance before it begins replicating, when conjugation progeny resumed vegetative growth. The following observations support the former explanation.

When DCL1 knockout cells with defective Mics were crossed with wild-type cells, chromosome condensation and segregation in the first (Fig. 4E,F) and second (Fig. 4G) meiosis in the DCL1 knockout cells, but not in the wildtype cells with which they were paired, were abnormal, and resulted in Mics that were eliminated after meiosis (Fig. 4H). In these matings, one haploid meiotic product produced in the wild-type cells divided once to make two haploid pronuclei (Fig. $4 \mathrm{H})$, one of which then migrated into the DCL1 knockout cell with which it was paired, as in normal conjugation. However, the DCL1 knockout cell lacked pronuclei that could be reciprocally transferred to the wild-type cell or could be fertilized by the migrating wild-type pronucleus (Fig. 4I,J). In this type of conjugation, called Round I genomic exclusion, the haploid, wild-type pronuclei in both cells of the pair then become diploid by endoreplication (Karrer 2000). The result of this process is that the defective Mic is eliminated and is replaced by a new "rejuvenated" wild-type Mic in both parents of the cross. Importantly, development of new Macs does not occur, so the Macs in both cells remain unchanged. The paired cells then abort conjugation and separate. This type of conjugation is typically observed when cells containing defective Mics are mated with normal cells.

Using the approach described above, rejuvenated Round I, DCL1 knockout cells (DCL1 knockout RI cells) were obtained (see Materials and Methods). These strains had normal size Mics after Round I mating (Figs. 4K, 5A,B), but lost much of their Mic DNA within $\sim 60$ fissions (Fig. 4L). Somatic DCL1 knockout cells, in which all Mac copies of the DCL1 gene were disrupted (Fig. 3C), also lost most of their Mic DNA (Fig. 4M). In both of these cases, Mic chromosome loss in DCL1 cells occurred without the formation of new Mics during conjugation, indicating that DCL1 expressed during vegetative growth is required for the maintenance of Mic chromosomes.

\section{DCL1 is required for accurate chromosome segregation during mitosis}

The small, DNA-poor Mic phenotype of DCL1 knockout cells is suggestive of a defect in mitosis of the Mic. In $\sim 50 \%$ of dividing Mics of the DCL1 knockout RI cells (Supplementary Fig. S3A), two daughter Mics were connected by DNA (anaphase bridge) (Fig. 4N) or a piece of DNA (a lagging chromosome or acentric chromosome fragment) was left between the recently divided Mics (Fig. 4O). These phenotypes were rare in wild-type strains (Supplementary Fig. S3A). These abnormal mito- 
ses should cause gradual loss of Mic chromosomes during vegetative growth. Evidence implicating Dicer-like proteins in centromere function, either for establishing proper centromere structure and/or for proper recruitment of cohesin, has been described in Schizosaccharomyces pombe and in human cells (Hall et al. 2003; Fukagawa et al. 2004). DCL1 knockout cells were also more sensitive than wild-type cells to oryzalin (Supplementary Fig. S3B,C), a microtubule destabilizing drug (Strachen and Hess 1983; Morejohn et al. 1987). These observations suggest that centromere function in Tetrahymena is similarly affected by the absence of DCL1 and that a requirement for Dicer-like proteins in centromere function is probably conserved among eukaryotes. Alternatively (or additionally), telomere function may be affected in DCL1 knockout cells, because anaphase bridges and lagging chromosomes or chromsome fragments have been observed in Tetrahymena with mutant telomeres (Kirk et al. 1997) and a role for an RNAi process in telomere has been reported (Hall et al. 2003).

\section{DCL1 is required for crescent formation in meiotic prophase}

In wild-type cells, the Mics adopt an elongate crescent shape (Fig. 5C) at meiotic prophase with the telomeres clustered at one end (D. Cassidy-Hanley and P.J. Bruns,

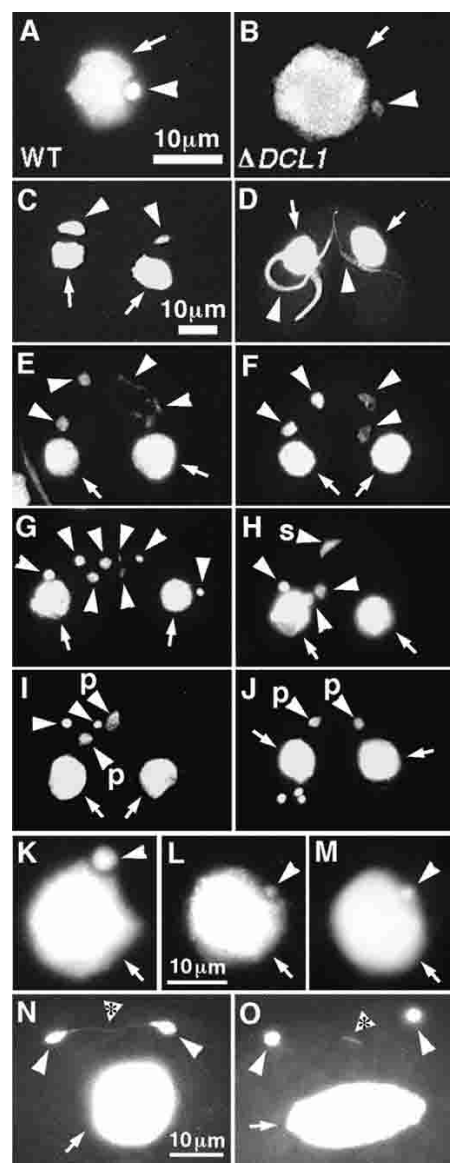

pers. comm.), making it likely that centromeres are clustered at the other end. This stage resembles the "bouquet" or "horsetail" stages in other eukaryotes, and, like those stages, is probably important in the alignment of homologous meiotic chromosomes (Scherthan 2001). When two DCL1 knockout RI strains were crossed, fully elongated crescents never formed (Fig. 5D). This defect was not due to loss of mitotic chromosomes during vegetative growth because, when DCL1 knockout RI cells or DCL1 knockout cells exhibiting Mic chromosome loss (see Fig. 4D) were mated with wild-type cells, allowing exchange of protein between the wild-type and DCL1 knockout cell (see Fig. 2), their Mics can make normally elongated crescents. These results argue that Dcllp expressed during meiotic prophase is required for crescent formation. Hall et al. (2003) reported that disruption of the RNAi machinery in $S$. pombe also disrupts the horsetail in meiosis, suggesting that a role for RNAi in the chromosome-pairing stages of meiosis may be a general phenomenon.

DCL1 is required for the fidelity of chromosome segregation during meiosis and pre/postzygotic nuclear divisions

In addition to affecting meiotic prophase, absence of DCL1 also affected events later in meiosis. In DCL1

Figure 4. $D C L 1$ is required for Mic chromosome maintenance. $(A, B)$ Comparison of wild-type $(A)$ and DCL1 knockout $(B)$ cells. The log-phase growing cells were fixed and stained with DAPI. The Mics in DCL1 knockout cells contain much less DNA than those of wild-type cells. $A$ and $B$ share the same scale bar shown in A. $(C-I)$ The Mics of DCL1 knockout cells cannot transmit genetic material to the next generation. Wild-type cells and DCL1 knockout cells were crossed, and the fixed cells were stained with DAPI. Mic abnormalities suggest that wild-type and DCL1 knockout cells were at left and right, respectively. Cells were in stages of early crescent (meiotic prophase; Stage II) $(C)$, late crescent (meiotic prophase; Stage IV) $(D)$, first meiotic division completed $(E, F)$, second meiotic division completed $(G)$, prezygotic mitosis $(H)$, pronuclear (unilateral) exchange $(I)$, and pronuclear (unilateral) exchange completed $(J)$. For stages, see Sugai and Hiwatashi (1974) and Cole et al. (1997). The Macs and the Mics are marked with arrows and arrowheads, respectively. In $H$, the selected, mitotically dividing haploid Mic is marked with an s, and in $I$ and $J$, pronuclei are marked with a p. $C-J$ share the same scale bar shown in $C$. $(K, L)$ A DCL1 knockout RI strain loses Mic chromosomes during vegetative growth. $D C L 1$ knockout RI cells ( $\triangle D C L 1-14 \mathrm{~A}$ RI) were fixed at about $12(K)$ and $60(L)$ fissions after Round I genomic exclusion and stained with DAPI. (M) A DCL1 somatic knockout strain loses Mic chromosomes. DCL1 somatic knockout cells in interphase were fixed and stained with DAPI. $K-M$ share the same scale bar shown in $L$. $(N, O)$ DCL1 knockout cells show lagging chromosomes during Mic mitosis. DCL1 knockout $\mathrm{RI}$ cells in late stages of Mic mitosis were fixed and stained with DAPI. Two daughter Mics were often connected by DNA ( $N$, arrowhead with asterisk); what appear to be chromosomes or chromosome fragments were often left between the daughter Mics $(O$, arrowhead with asterisk). $N$ and $O$ share the same $10-\mu \mathrm{m}$ scale bar shown in $N$. In all pictures, the Macs and the Mics are marked with arrows and arrowheads, respectively. 
knockout RI cells, after short crescent formation, chromosomes were not fully condensed, and the first and second meiotic divisions were severely affected (Fig. 5F). In most of the mating cells, the chromosomes did not segregate equally to daughter nuclei, resulting in four meiotic products of different sizes (Fig. $5 \mathrm{H}$ ). In post-meiotic stages, selection of the haploid Mic product and the third prezygotic division frequently failed (Fig. 5J). In pairs where the third prezygotic division had been successful in only one side of the pair, uniparental pronuclear transfer occurred (Fig. 5L) and is likely to be followed by Round I genomic exclusion. In $\sim 5 \%$ of the pairs, the third prezygotic division, pronuclear exchange, and postzygotic nuclear divisions occurred (Fig. 5N), but not all nuclear divisions proceeded normally. Failure in postzygotic nuclear divisions resulted in abnormal numbers and sizes of Mics and of Mac anlagens at the end of development (Fig. 5O-T). We believe these abnormalities also were caused by defects in centromere function in the meiotic and pre/post zygotic divisions, although we cannot exclude the possibility that the defects in crescent formation, chromosome condensation, or telomere function affected these later conjugation events.

\section{DCL1 is required for accumulation of $\operatorname{scn} R N A$}

Localization of Dcllp in the Mic during early conjugation suggested that it could be involved in the processing of the nongenic Mic transcripts to scnRNAs. To test this, two DCL1 knockout RI strains containing morphologically normal Mics, but lacking DCL1 genes in their Macs, were crossed, and total RNA extracted at different times was analyzed (Fig. 6A). In contrast to wild-type cells, $\sim 28$ nt scnRNAs were not detectable in DCL1 knockout RI cells. Thus, DCL1 is required for accumulation of the scnRNAs. Interestingly, $\sim 24 \mathrm{nt}$ small RNAs, which were present but difficult to detect in wildtype cells, increased in DCL1 knockout RI strains (Fig. 3). We speculate that dsRNA substrates normally digested by Dcllp in the Mic of wild-type cells become available for digestion by one of the other two Dicer-like enzymes when Dcllp is absent.

\section{Nongenic Mic transcripts overaccumulate in DCL1 knockout cells}

It was possible that defective crescent formation in meiotic prophase in DCL1 knockout RI cells (Fig. 5) indirectly inhibited Mic crescent transcription, and therefore, scnRNAs could not be produced. Alternatively, if Mic nongenic transcription occurs normally in DCL1 knockout RI cells, and the bidirectional transcripts in wildtype cells are processed to scnRNAs by Dcllp, unprocessed transcripts should accumulate in the absence of Dcllp. To distinguish these, we analyzed the transcription of both strands of a well-studied, nongenic Mic-specific sequence, the M-region (Austerberry and Yao 1988), using Northern blots (Fig. 6). In both wild-type and DCL1 knockout RI cells, heterogeneous RNAs, mainly around $0.2-1 \mathrm{~kb}$, corresponding to both strands of the M-region, were detected (Fig. 6C), indicating that defec-

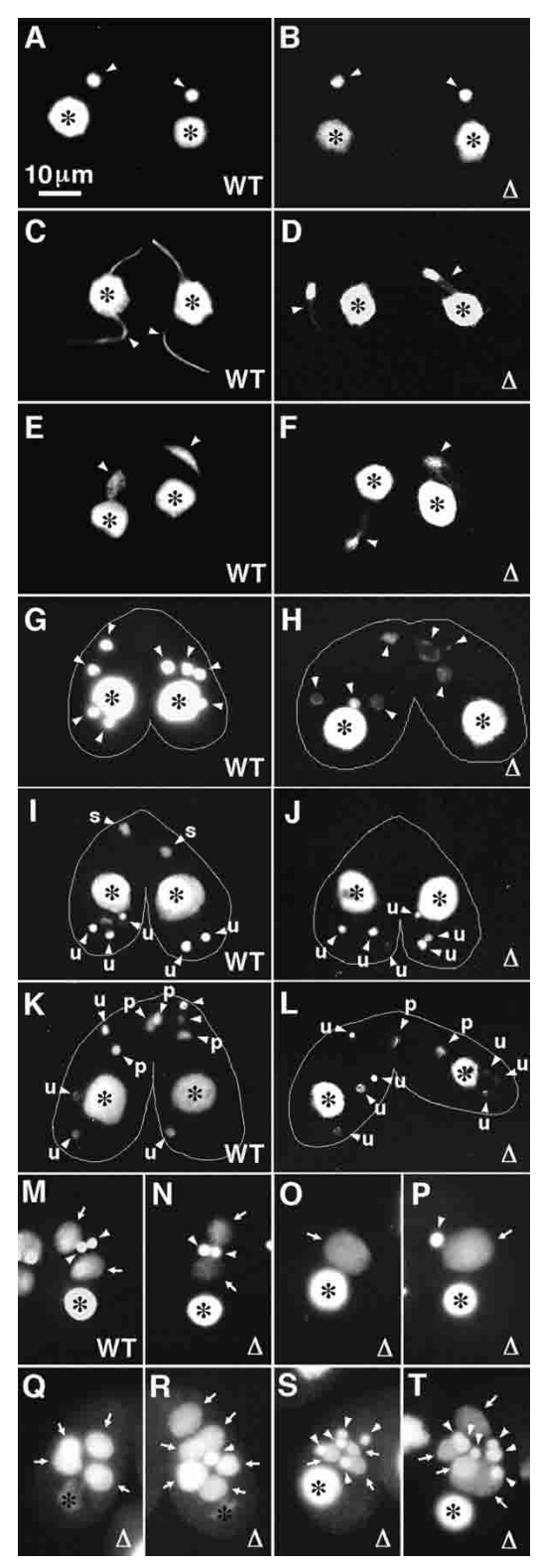

Figure 5. DCL1 knockout cells have defects in Mic chromosome dynamics during conjugation. Two wild-type strains (WT) or two Round I DCL1 knockout strains $(\Delta)$ were mated, fixed, and stained with DAPI. $(A, B)$ Immediately after pairing. $(C, D)$ Meiotic prophase (crescent stage). $(E, F)$ Chromosome condensation. $(G, H)$ After the second meiotic division. $(I, J)$ Nuclear selection. $(K, L)$ Pronuclear exchange. $(M-T)$ Nuclear alignment stage. (O) Only a new Mac developed. $(P)$ A Mac and a Mic developed. (Q) Four Macs developed. (R) Six Macs and two (one is not visible) Mics developed. (S) Three (incomplete) Macs and five Mics developed. (T) Four Macs and six Mics developed. (Asterisks) (parental) Macs; (arrowheads) Mics; (arrows) developing new Macs; (s) selected haploid Mics; (u) unselected, eliminating Mics; (p) pronuclei. In $G-L$, outlines of cells were traced. For stages, see Cole et al. (1997). All pictures share the same scale bar shown in $A$. 


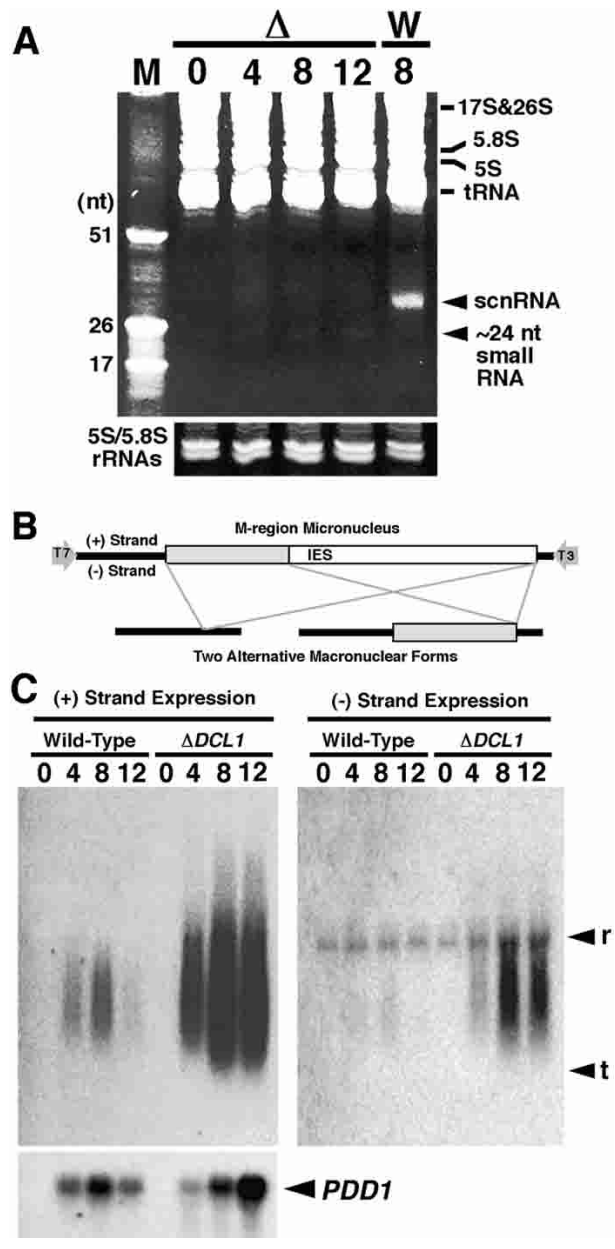

Figure 6. Expression of scnRNA and nongenic Mic transcripts. (A) Total RNA was extracted from mating DCL1 knockout RI cells $(\Delta)$ at $0,4,8$, and $12 \mathrm{~h}$ post-mixing or from wild-type cells $(\mathrm{W})$ at $8 \mathrm{~h}$ post-mixing. RNA from $5 \times 10^{4}$ cells was analyzed in $12 \%$ acrylamide-urea gel and stained with ethidium bromide. In vitro-transcribed 17,26 , and $51 \mathrm{nt}$ RNAs were used as markers (M). The gel was partially destained, and the amounts of $5 \mathrm{~S}$ and 5.8S rRNAs are shown as loading controls. $(B)$ Schematic drawing of the Mic M-region sequence (top) and its two alternatively processed Mac forms (bottom). (Open box) IES; (gray box) IES eliminated only in the long-deletion form; (horizontal bars) Mac-destined sequences (MDSs). Promoters for T3 and T7 RNA polymerases were added at the $5^{\prime}$ and $3^{\prime}$ ends of Mic M-region sequence, respectively. $(C)$ Northern blot made with total RNA extracted from equal numbers of wild-type and DCL1 knockout RI cells at $0,4,8$, and $12 \mathrm{~h}$ post-mixing and hybridized with probes complementary to $(+)$ strand (left) and (-) strand (right) of the Mic M-region made by in vitro transcription with T3 and T7 RNA polymerase, respectively. Positions for $17 \mathrm{~S}+28 \mathrm{~S}$ rRNAs and tRNAs are marked with $\mathrm{r}$ and $\mathrm{t}$, respectively. The blot used for $(+)$ strand probe was reprobed with a $P D D 1$ probe as a marker for conjugation (left, bottom). Increased expression of PDD1 in DCL1 knockout cells at late stages of conjugation ( $12 \mathrm{~h}$ post-mixing) probably reflected arrested conjugation in the late stages.

tive crescent formation in DCL1 knockout RI cells does not affect Mic transcription. Accumulation of these nongenic transcripts in DCL1 knockout RI strains was much higher than in the wild-type strains (Fig. 6C), arguing that Dcllp is the enzyme that processes the Mic transcripts to scnRNAs.

\section{DCL1 is required to produce viable progeny}

Although DCL1 knockout cells had severe defects in mitotic and meiotic chromosome segregation, a few conjugants were able to proceed through meiosis, fertilization, and postzygotic division stages to become exconjugants (Fig. 5). To determine whether these cells were viable, two DCL1 knockout RI strains were mated, and their progeny were analyzed. Because the newly introduced Mics of these strains were derived from the Mics of strain CU427 that had cycloheximide resistance (cy-r) genes that are lacking in the DCL1 knockout Macs, progeny should be distinguishable from their parents by their cy-r. Although $1 \times 10^{7}$ cells of each strain were mixed for mating and around $5 \%\left(\sim 1 \times 10^{6}\right)$ of the cells examined cytologically were exconjugants before selection was initiated, no viable progeny were obtained. In contrast, when DCL1 knockout RI cells were mated with strain B2086 cells, which lack cy-r genes in both Macs and Mics, their conjugation process was almost normal, and cy-r progeny were obtained (data not shown). Thus, the reintroduced Mic of DCL1 knockout RI strain cells can undergo meiosis and contribute a functional cy-r gene to the zygotic nucleus if Dcllp was supplied from the wildtype (for DCL1) partner by cytoplasmic exchange. These results indicate that the inability of two DCL1 knockout strains to make viable conjugation progeny is due to the loss of parentally expressed DCL1 during conjugation, and not to defects accumulated in the Mic during vegetative mitosis. We conclude that DCL1 expressed during conjugation is required for making viable progeny.

DCL1 is required for accumulation of methylated H3 Lys 9 in the developing Mac

All strains containing mutations that block IES elimination studied to date also fail to produce viable progeny (Coyne et al. 1999; Nikiforov et al. 1999; Mochizuki et al. 2002; Liu et al. 2004). Because DCL1 is required for making scnRNA (Fig. 6A) involved in genome rearrangement (Mochizuki et al. 2002; Mochizuki and Gorovsky 2004a), failure to recover viable progeny from matings of DCL1 knockout RI cells could be due to defects in genome rearrangement. However, the low frequency of successful exconjugant formation $(-5 \%)$ in DCL1 knockout strains limited the ability to directly examine IES elimination in the absence of DCL1 expression. Because methylation of Lys 9 on histone H3 (H3 Lys 9) occurs specifically on eliminating IESs (Taverna et al. 2002), and is required for IES elimination (Liu et al. 2004), we used in situ immunofluorescence to analyze methylation of H3 Lys 9 as a marker for IES elimination in DCL1 knockout RI cells. Methylated H3 Lys 9 localization in the developing new Macs was easily detected in wild-type cells 
(Fig. 7A), but not in DCL1 knockout RI cells (Fig. 7C). Because meiosis and postzygotic mitoses were affected in the majority of mating DCL1 knockout RI cells (Fig. 5), the absence of methylated H3 Lys 9 in the developing new Macs could be caused by a general failure of nuclear differentiation. To test this possibility, we studied the localization of Pddlp, a chromodomain protein that is first localized in the parental Mac and then in the developing new Mac (Madireddi et al. 1996). Pddlp also directly binds to methylated H3 Lys 9 (Taverna et al. 2002) in vitro and is required for IES elimination (Coyne et al. 1999). As shown in Figure 7E and G, Pddlp localized normally in the developing new Mac in DCL1 knockout RI strains. Thus, with regard to Pdd1p localization, new Mac differentiation occurred normally, even though methylation of H3 Lys 9 was not detected. These results argue that methylation of H3 Lys 9, and the IES elimination that is dependent on it, are specifically affected by the absence of DCL1. We conclude that DCL1 is required for IES elimination.

\section{Discussion}

Dcl1p has distinct functions in genome rearrangement and in chromosome segregation

Four observations lead us to conclude that Dcllp, a Dicer-like RNase III protein, is the enzyme that pro-

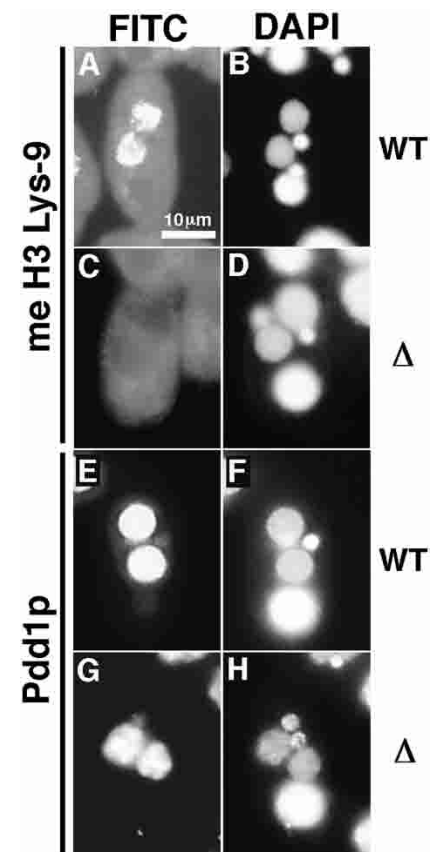

Figure 7. Expression of methylated $\mathrm{H} 3$ Lys 9 and Pdd1p. $(A-D)$ Localization of methylated H3 Lys 9. Wild-type $(A, B)$ or DCL1 knockout RI strain $(C, D)$ at nuclear alignment stage (12 h postmixing) were stained with anti-methylated H3 Lys 9 antibody $(A, C)$ or with DAPI $(B, D)$. $(E-H)$ Localization of Pdd1p. Wildtype $(E, F)$ or DCL1 knockout RI strain $(G, H)$ at nuclear alignment stage were stained with anti-Pdd $1 \mathrm{p}$ antibody $(E, G)$ or with DAPI $(F, H)$. All photos share the scale bar shown in $A$. cesses nongenic Mic transcripts to scnRNAs and is required for genome rearrangement. First, Dcllp-HA was localized in the Mic during meiotic prophase and meiosis (Fig. 2) at the time and site where crescent transcription was observed (Sugai and Hiwatashi 1974; Martindale et al. 1985) and at the same time that nongenic Mic transcripts (Chalker and Yao 2001) and scnRNAs (Mochizuki et al. 2002) are first expressed. Second, DCL1 is required for accumulation of scnRNAs (Fig. 6A). Third, nongenic Mic transcripts for the M-region IES overaccumulate in DCL1 knockout cells (Fig. 6C). Lastly, methylation of histone H3 Lys 9, which in Tetrahymena specifically occurs on eliminating IESs (Taverna et al. 2002), and is required for IES elimination (Liu et al. 2004), was not observed in developing new Macs in DCL1 knockout cells (Fig. 7). This is the first experimental evidence that links the nongenic Mic transcripts to genome rearrangement through scnRNAs.

DCL1 also is required for accurate Mic chromosome segregation in mitosis and meiosis. First, in DCL1 knockout cells, severe defects were observed in maintenance of mitotic Mics (Fig. 4). Second, chromosome segregation defects were observed during Mic mitosis in the absence of DCL1 (Fig. 4N,O). Third, chromosomes were inaccurately segregated to daughter nuclei during meiosis and pre/postzygotic mitoses in DCL1 knockout cells (Fig. 5). It is also likely that DCL1 has functions during meiotic crescent formation that are independent of its effects on chromosome segregation (Fig. 5).

\section{Different functions of Dcl1p probably reflect associations with different PPD/Argonaute proteins}

Twilp, a PPD/Argonaute family protein is required for scnRNA accumulation and genome rearrangement, but no Mic segregation defects were observed in TWI1 knockout cells (Mochizuki et al. 2002). No RNAi-like mechanism has been described that does not require a PPD/Argonaute family protein (Meister and Tuschl 2004). Therefore, genome rearrangement and chromosome segregation should be controlled by distinct RNAirelated mechanisms that both use Dcllp. We predict that one or more of the 11 other PPD proteins in Tetrahymena (K. Mochizuki, T. Noto, and M.A. Gorovsky, unpubl.) will be involved in Mic chromosome segregation.

The three Dicer-like genes in Tetrahymena probably have distinct functions

We identified two other dicer-like genes (DCR1 and DCR2; Fig. 1) that could not compensate for loss of function of DCL1. Disruption of DCR1 showed no obvious phenotype in either vegetative growth or in conjugation, and did not affect chromosome segregation, scnRNA expression, or genome rearrangement (K. Mochizuki and M.A. Gorovsky, unpubl.). DCR2 was essential for vegetative growth (K. Mochizuki and M.A. Gorovsky, unpubl.). Thus, while DCR1 and DCR2 could have func- 
tions that are partially redundant with $D C L 1$, and we cannot exclude the possibility that one or both of them function sequentially to process the nongenic Mic transcripts to scnRNAs like Drosha and Dicer homologs in metazoans, they are likely to participate in processes other than chromosome segregation and genome rearrangement. These two Dicer-like enzymes and the multiple PPD proteins may be involved in more conventional RNAi/post transcriptional gene silencing, endogenous micro RNA induced gene silencing, or virus/ transposon-induced transcriptional gene silencing (Meister and Tuschl 2004), although none of these phenomena has yet been described in Tetrahymena.

\section{Refining the scnRNA model}

We proposed the scnRNA model to explain how IESs, lacking any consensus sequences, are recognized during Mac development using a RNAi-related mechanism (Mochizuki et al. 2002; Mochizuki and Gorovsky 2004b). In this model, we proposed that the processing of nongenic Mic transcripts to scnRNAs occurred in the cytoplasm or in the parental Mac. This prediction was dependent on the observations that Twilp, required for accumulation of scnRNA, localizes first in the cytoplasm and then transfers to the parental Mac, but is never observed in the Mic (Mochizuki et al. 2002) and on the fact that Dicer activity was reported to be cytoplasmic in other systems. However, we recently demonstrated that Twip is required for scnRNA stability, not synthesis (Mochizuki and Gorovsky 2004a). Also, the present study shows that Dcllp is required for processing of nongenic Mic transcripts to scnRNAs (Fig. 6) and is detectable only in the meiotic Mic (Fig. 2). Thus, it is likely that the processing of nongenic Mic transcripts to scnRNAs occurs in the meiotic Mic followed by transfer of scnRNAs to the cytoplasm, where they interact with Twilp (Mochizuki and Gorovsky 2004a) prior to their transfer to the old (and then the new) Mac.

\section{Timing of crescent transcription, processing of scnRNAs, and expression of nongenic Mic transcripts}

scnRNAs were not detected and nongenic Mic transcripts overaccumulated in DCL1 knockout cells, suggesting that Dcllp is the major, if not the only, enzyme that processes nongenic Mic transcripts to scnRNAs. Dcllp was localized in the Mic during meiosis (Fig. 2), but was not observed after the second meiotic division ( $\sim 4 \mathrm{~h}$ post-mixing) (Fig. $2 \mathrm{H}$ ). In contrast, scnRNAs were detected until late stages of conjugation $(2 \sim 14 \mathrm{~h}$ postmixing) and can accumulate in somatic PDD1 knockout cells only after zygotic expression of Pdd1p (Mochizuki et al. 2002). Autoradiographic analyses of conjugating cells pulse labeled with tritiated uridine revealed that RNA synthesis in the Mic (crescent transcription) is detectable only during meiotic prophase (Sugai and Hiwatashi 1974; Martindale et al. 1985) and RNA polymerase II is localized in Mics only during meiotic prophase
(Mochizuki and Gorovsky 2004c). On the other hand, nongenic Mic transcripts derived from the M-region IES continue to accumulate even after meiosis, in mid stages (5 to $\sim 8 \mathrm{~h}$ post-mixing) of conjugation (Fig. 6C; Chalker and Yao 2001) and some IESs (Tt2512-related) do not appear to accumulate until mid stages $(\sim 7 \mathrm{~h}$ post-mixing) of conjugation (Chalker and Yao 2001). Thus, the expected timing of Mic RNA/scnRNA synthesis and the accumulation pattern of the nongenic Mic transcripts are not completely correlated. Thus, although our results argue that a precursor-product relationship exists between the nongenic Mic transcripts and scnRNAs, it is unlikely that all nongenic RNAs are derived directly from Mic transcripts. One possible explanation for this discrepancy is that the nongenic Mic transcripts are transcribed in meiotic prophase and are subsequently amplified by an RNA-dependent RNA polymerase (RdRP). Tetrahymena has a gene encoding RdRP, whose function is not yet known. Because the majority of Dcllp is not detectable after meiosis, nongenic Mic transcripts detected in later stages of conjugation may never get processed into scnRNAs. Alternatively, low levels of Dcllp or one of the other dicers may be present in the cytoplasm or in the Mac, and could process the nongenic transcripts later in conjugation. Because RdRP activity itself can produce small RNAs similar to siRNAs in vitro (Makeyev and Bamford 2002), RdRP may directly produce scnRNAs.

\section{An RNAi-related mechanism is probably involved in centromere function}

Two observations suggest that $D C L 1$ is required for centromere function. First, in DCL1 knockout cells, severe defects were observed in maintenance of mitotic Mics, which contain centric chromosomes, but no obvious defects were detected in amitotic Macs, whose chromosomes behave as if they are acentric (Fig. 4). Second, DCL1 knockout cells were hypersensitive to a microtubule destabilizing drug that should disturb microtubule assembly on the centromere (Supplementary Fig. S3B,C).

In S. pombe, small RNAs homologous to both strands of centromeric repeat sequences have been observed (Reinhart and Bartel 2002) and components of the RNAi machinery are required for accumulation of the small RNAs and for centromere function (Hall et al. 2002, 2003; Provost et al. 2002; Volpe et al. 2002, 2003). Thus, the unidentified centromeric sequences in Tetrahymena are also probably transcribed bidirectionally to make dsRNAs that are processed by Dcllp during vegetative growth. To date, neither transcription (Gorovsky and Woodard 1969), nor any transcription-related factors such as histone H2A.Z (Allis et al. 1986; Stargell et al. 1993), TATA-binding protein (Stargell and Gorovsky 1994), or RNA polymerases I, II, or III (Mochizuki and Gorovsky 2004c), have been detected in Mics in growing vegetative cells. This could reflect the low number of centromeric sequence per genome and/or low levels of centromeric RNA transcription. Alternatively, it is possible that Dcllp is involved in processing of miRNAs 
originating in Macs that could regulate genes involved in chromosome segregation.

\section{IESs, heterochromatin, and centromeric regions}

Mics have IESs and contain chromosomes with centromeres, while Macs lack IESs and contain chromosomes that behave as if they are acentric, suggesting that some IESs act as centromeres on Mic chromosomes (Coyne et al. 1996). Mic chromosomes adopt a "V-shape" in mitosis (Bruns et al. 1983) and in the second meiotic division (Cole et al. 1997), and appear to be monocentric, with a single point or regional centromere near the center of each chromosome. The existence of X-shape chromosomes in the first meiotic division also suggests that homologous chromosomes attach at centrally located centromeres (Cole et al. 1997). It should be very interesting to determine how centromeres, which themselves may be special IESs, are affected by an RNAi-related mechanism that should be distinct from the RNAi-related process involved in genome rearrangement.

The centromere region is heterochromatic in many eukaryotes, and accumulation of chromodomain proteins, such as HP1/Swi6 and methylation of H3 Lys 9, are hallmarks of heterochromatin (Richards and Elgin 2002). Accumulation of HP1/Swi6 and methylated H3 Lys 9 on heterochromatin are dependent on an RNAi-related mechanism in S. pombe (Hall et al. 2002; Volpe et al. 2002), Arabidopsis (Zilberman et al. 2003), and Drosophila (Pal-Bhadra et al. 2004). However, none of the currently known Tetrahymena chromodomain proteins (Madireddi et al. 1996; Smothers et al. 1997; Huang et al. 1998; Nikiforov et al. 2000) or H3 Lys 9 methylation (Strahl et al. 1999; Taverna et al. 2002) has been detected in the Mic of vegetative cells. Again, it is possible that small amounts of centromere sequence per genome might have prevented detection of these heterochromatin-associated factors. But, the fact that substitution of H3 Lys 9 with glutamine does not show any Mic (or other) defects in vegetative cells (Liu et al. 2004) argues against this view. Alternatively, because the entire complement of Mic chromosomes is transcriptionally inactive in vegetative cells, the transcriptionally silent chromatin usually associated with centromeres and required for their proper function in other organisms may be determined by a different mechanism in Tetrahymena, rather than by the assembly of centromeric heterochromatin typical of most other eukaryotes. If this is indeed the case, RNAi-like mechanisms might play two distinct roles in centromere biogenesis, one to establish a transcriptionally silent environment, and another to establish a yet unknown aspect required for proper function of centromeres in mitotic chromosome segregation.

\section{Materials and methods}

\section{Strains and culture conditions}

Wild-type B2086, CU427, and CU428 strains of Tetrahymena thermophila (provided by Dr. P.J. Bruns, Cornell University,
Ithaca, NY) were grown in SPP medium (Gorovsky et al. 1975) at $30^{\circ} \mathrm{C}$. For conjugation, log-phase cells of different mating types were washed, starved $\left(16-24 \mathrm{~h}\right.$ at $\left.30^{\circ} \mathrm{C}\right)$, and mixed in 10 $\mathrm{mM}$ Tris (pH 7.5).

\section{Identification and characterization of dicer-like genes}

Three dicer-like genes were identified in the Tetrahymena genome database (http://tigrblast.tigr.org/er-blast/index.cgi?project= ttg). Parts of their cDNA sequences were determined by sequencing RT-PCR products. A 3'-RACE was used for all three genes to determine their transcription termination sites. For $D C L 1,5^{\prime}$-RACE was performed to identify the putative transcriptional start sites. cDNA sequences of DCR1, DCR2, and DCL1 can be found in DDBJ/EMBL/GenBank AB182479, $\mathrm{AB182480}$, and $\mathrm{AB182481}$, respectively.

\section{Construction of DCL1-HA strains}

HA coding sequence (TATCCTTATGATGTTCCTGATTAT GCT) was inserted just before the stop codon of DCL1 by overlapping PCR. The primers used for PCR were DCL15'Tag: 5'CGCTCGAGTCTAATTTATAGAGGATTGCAACC-3' (XhoI site is underlined); DCL1HARV: 5'-AGGAACATCATAAG GATATACTTACTTTCCTTAGAATATTAATCC-3' (HA coding sequence is underlined); DCL1HAFW: 5'-CCTTATGAT GTTCCTGATTATGCTTGAATGAGAGGATGGATTTA-3' (HA coding sequence is underlined); DCL13'Tag: 5'-GCGGATCCT TAATTTATCTTTGCACC-3' (BamHI site is underlined).

DCL15'Tag and DCL1HARV were used to amplify $\sim 0.5-\mathrm{kb}$ C-terminal coding sequence of DCL1, followed by HA sequence. Also, DCL1HAFW and DCL13'Tag were used to amplify the HA-encoding sequence, followed by the translational stop codon, the 3'UTR, and $\sim 1 \mathrm{~kb}$ of 3'flanking sequence. Then, these two fragments were combined by overlapping PCR using primers DCL15'Tag and DCL13'Tag. The amplified product was digested with XhoI and BamHI and inserted into pBlueScript SK|+) vector. Then, the neo3 cassette, conferring paromomycin (pm) resistance in Tetrahymena cells (Shang et al. 2002), was inserted in the NsiI site of the 3 '-flanking sequence of DCL1, resulting in $\mathrm{p} D C L 1$-HA.

$\mathrm{p} D C L 1-\mathrm{HA}$ was digested with XhoI and BamHI and introduced into the endogenous DCL1 locus of CU428 as described (Cassidy-Hanley et al. 1997). The endogenous wild-type Mac DCL1 loci were completely replaced by phenotypic assortment and selection in increasing concentrations of pm. Complete replacement was confirmed by Southern hybridization.

\section{Indirect immunofluorescent staining}

Cells were fixed, immobilized on cover glasses, and incubated in blocking solution as described (Mochizuki and Gorovsky 2004c). To localize Dcllp-HA, methylated histone H3 Lys 9, and Pdd1p, 1:200 dilution of mouse anti-HA antibody (16B12; Covance), 1:50 dilution of rabbit anti-dimethyl histone H3 Lys 9 antibody (Upstate Biotechnology), and 1:50 to 1:100 dilution of rabbit anti-Pdd1p (provided by Dr. C. David Allis, The Rockefeller University, New York, NY) were used, respectively. The samples were incubated with each antibody diluted in the blocking solution, followed by 1:250 diluted FITC-conjugated goat anti-mouse (for HA) or anti-rabbit (for Pdd1p and methylated histone H3) IgG antibodies (Zymed Labs Inc.) in blocking solution. The samples were incubated with $10 \mathrm{ng} / \mathrm{mL}$ DAPI in PBS and observed by fluorescence microscopy.

\section{Construction of DCL1 knockout strains}

To make the disruption construct, the genomic region, including the DCL1 gene $(805,257 \mathrm{~b}-809,765 \mathrm{~b}$ of Tetrahymena ge- 
nome database \#8254600, release November 2003), was amplified by PCR, inserted into pBlueScript $\mathrm{SK}(+)$ vector, and the internal BglII fragment was replaced by the neo3 cassette. Primers used for the PCR were 5'-CGCTCGAGTTCATTCCATAT CACTGTCTG-3' (XhoI site is underlined) and 5' -GCGGATCC TAAAATCTCTATTAAGGCATCTC-3' (BamHI site is underlined). B2086 and CU428 cells were mated, and the construct was introduced as described (Cassidy-Hanley et al. 1997). Two transformants that had neo3 in the DCL1 loci of both the Mac and Mic were obtained. The disrupted loci in the Mac were eliminated by phenotypic assortment in the absence of selection. The resulting heterozygous DCL1 germline knockout heterokaryons, which were pm-sensitive, were crossed, and individual pairs were isolated into drops of medium at 8 to $\sim 10 \mathrm{~h}$ post mixing. DCL1 knockout homozygous homokaryon strains, referred to as $\triangle D C L 1$ were selected from pm-resistant progeny by analyzing their genotypes by PCR. Complete elimination of the DCL1 gene in $\triangle D C L 1$ strains was confirmed by Southern hybridization. Two of these strains, $\triangle D C L 1-10$ and $\triangle D C L 1-$ 14A, lacking wild-type DCL1 genes in both their Macs and Mics, were used for further studies.

In the transformation described above, cells containing neo3 only in their Macs were also obtained. The endogenous wildtype Mac DCL1 loci in these "somatic" transformants were completely replaced with the disrupted loci by phenotypic assortment and selection in increasing concentrations of $\mathrm{pm}$. Complete replacement was confirmed by Southern hybridization.

\section{Round I genomic exclusion}

$\triangle D C L 1-10$ or $\triangle D C L 1-14 \mathrm{~A}$ homozygous heterokaryon cells were crossed with wild-type CU427 strain cells, and single pairs were isolated in drops of SPP medium at 7-8 h post-mixing. After pairs separated, each cell was isolated into a SPP drop and cultured. The resulting drop cultures were transferred to SPP medium in 96-well microtiter plates. Part of each culture was used to test for $\mathrm{pm}$ resistance in $120 \mu \mathrm{g} / \mathrm{mL}$ pm sulfate and $1 \mu \mathrm{g} / \mathrm{mL}$ $\mathrm{CdCl}_{2}$ in SPP. The sizes of Mics also were observed by DAPI staining. Pm resistant cells (derived from the $\triangle D C L 1$ side) with normal sized Mics (cells that had likely undergone Round I genomic exclusion) were identified. Round I genomic exclusion in these cells was confirmed by testing for absence of cycloheximide (cy) resistance, which could only have been obtained from the CU427 parent cell if normal conjugation or short circuit genomic exclusion (Karrer 2000) had occurred. The pm-resistant cells were further tested for the expected genotype of Round I cells by testing their ability to produce cy-resistant progeny when mated with wild-type CU428 or B2086 strains, which are homozygous for cy sensitivity in both their Macs and Mics. Production of cy-resistant progeny cells in this mating demonstrates that the pronucleus from CU427, conferring cy resistance, was successfully transferred to the $\triangle D C L 1$ cell, and that the resulting new Mic could produce a functional Mac. Round I progeny from $\triangle D C L 1-10$ and $\triangle D C L 1-14 \mathrm{~A}$ were named $\triangle D C L 1$ $10-\mathrm{RI}$ and $\triangle D C L 1$-14A-RI, respectively and used for further studies. $\triangle D C L 1-10-\mathrm{RI}$ and $\triangle D C L 1-14 \mathrm{~A}-\mathrm{RI}$ strains were used for conjugation experiments within $\sim 30$ fissions after Round I mating to reduce the possibility that their Mics would become severely hypodiploid by multiple replications in cells whose Macs could not express DCL1.

\section{$R T-P C R$}

First-strand cDNA was synthesized using StrataScript reverse transcriptase (Stratagene), $\sim 3 \mu \mathrm{g}$ of the total RNA as the tem- plate and random hexamer primers (Amersham-Pharmacia). For PCR, the following primers were used: 5'-AGGAATTTCAGC GTTTAGAAACGGTC-3' (2500 b-2525 b of GenBank AB102481) and 5'-CATAAAAGCACCCAACAACTG-3' (2670 b-2690 b). PCR was performed using the first-strand cDNA as a template, the primers above, and Go-Taq (Promega) as the DNA polymerase, with 42 cycles of $94^{\circ} \mathrm{C}$ for $30 \mathrm{sec}, 50^{\circ} \mathrm{C}$ for $30 \mathrm{sec}$, and $72^{\circ} \mathrm{C}$ for $60 \mathrm{sec}$.

\section{Observation of small RNAs (scnRNAs) and nongenic Mic transcripts}

Total RNA isolation, Northern blotting analysis, and observation of the small RNAs were performed as described (Mochizuki et al. 2002). Northern blots were incubated in prehybridization solution $(5 \times$ SSPE, $50 \%$ formamide, $5 \times$ Denhart's solution, $0.1 \%$ SDS, $50 \mu \mathrm{g} / \mathrm{mL}$ herring sperm DNA) at $42^{\circ} \mathrm{C}$ for $2 \mathrm{~h}$, and hybridized with the plus or minus strand M-region riboprobes (see below) in the hybridization solution (prehybridization solution $+5 \%$ dextran sulfate) at $42^{\circ} \mathrm{C}$ for $16-24 \mathrm{~h}$. The membranes were washed in $2 \times \mathrm{SSC}, 0.1 \% \mathrm{SDS}$ at $42^{\circ} \mathrm{C}$ for $15 \mathrm{~min}$; in $1 \times \mathrm{SSC}$, $0.1 \%$ SDS at $55^{\circ} \mathrm{C}$ for $15 \mathrm{~min}$; in $0.5 \times \mathrm{SSC}, 0.1 \%$ SDS at $55^{\circ} \mathrm{C}$ for $15 \mathrm{~min}$; in $0.25 \times \mathrm{SSC}, 0.1 \%$ SDS at $55^{\circ} \mathrm{C}$ for $15 \mathrm{~min}$, and then exposed to the X-ray film. The membrane was stripped and reprobed with $P D D 1$ probe (see below). The membrane was washed as above, except at $60^{\circ} \mathrm{C}$.

\section{Hybridization probes}

The Mic genomic DNA region, including the M-region IES (nucleotides 28-1194 of GenBank M21936), was amplified by PCR using primers that had promoter sequences of $\mathrm{T} 7$ or $\mathrm{T} 3$ RNA polymerases at their $5^{\prime}$-end giving products were flanked by $\mathrm{T} 7$ and $\mathrm{T} 3$ promoters. The primers used for PCR were 5'-CGTAATACGACTCACTATAGGGAGAGTTTATTCTGA AATTTATCCTATG-3' (T7 RNA polymerase promoter sequence is underlined) and $5^{\prime}$-CGAATTAACCCTCACTAAAG GGAGAAGGATTCAACAAAGTAAGC-3' (T3 RNA polymerase promoter sequence is underlined).

The PCR product was gel purified and used for in vitro transcription reactions. A total of $0.5 \mu \mathrm{g}$ of template DNA, $1.33 \mu \mathrm{M}$ $\left[\alpha-{ }^{32} \mathrm{P}\right] \mathrm{UTP}(3000 \mathrm{Ci} / \mathrm{mmol}$, Amersham Bioscience), $0.2 \mathrm{mM}$ ATP, $0.2 \mathrm{mM}$ CTP, $0.2 \mathrm{mM}$ GTP, $10 \mu \mathrm{M}$ UTP, 12 U RNasin (Promega), and 50 U T7 RNA polymerase (New England Biolabs), or 20 U T3 RNA polymerase (Fermentas) were mixed in a $10-\mu \mathrm{L}$ solution and incubated at $37^{\circ} \mathrm{C}$ for $2 \mathrm{~h}$. DNA template was digested with DNase I (RNase free, Sigma) at $37^{\circ} \mathrm{C}$ for 20 min, and labeled RNA was purified with Quick Spin Columns (Sephadex G-50, Roche).

For the PDD1 probe, nucleotides 631-943 of GenBank TTU66363 were amplified by PCR and used as the template for labeling by random priming.

\section{Viability test}

Two starved DCL1 knockout RI strains ( $\triangle D C L 1-10-\mathrm{RI}$ and $\triangle D C L 1-14 \mathrm{~A}-\mathrm{RI})$ or a $D C L 1$ knockout RI strain ( $\triangle D C L 1-14 \mathrm{~A}-\mathrm{RI})$ and a wild-type strain (B2086) were mixed to allow conjugation, then refed by adding an equal amount of $2 \times$ SPP medium at 24 $\mathrm{h}$ post-mixing. Three hours after refeeding, $15 \mu \mathrm{g} / \mathrm{mL}$ of cy was added, the cultures were aliquoted to 24-well culture plates that were incubated 3-6 d, until either all cells were dead or cyresistant progeny grew.

\section{Acknowledgments}

We thank Josephine Bowen for critical reading of the manuscript. This work was supported by grant GM21793 from the 
National Institutes of Health. Preliminary sequence data were obtained from The Institute for Genomic Research at http:// www.tigr.org.

\section{References}

Allis, C.D., Richman, R., Gorovsky, M.A., Ziegler, Y.S., Touchstone, B., Bradley, W.A., and Cook, R.G. 1986. hvl is an evolutionarily conserved H2A variant that is preferentially associated with active genes. J. Biol. Chem. 261: 1941-1948.

Austerberry, C.F. and Yao, M.C. 1988. Sequence structures of two developmentally regulated, alternative DNA deletion junctions in Tetrahymena thermophila. Mol. Cell Biol. 8: 3947-3950.

Bruns, P.J., Brussard, T.B., and Merriam, E.V. 1983. Nullisomic Tetrahymena. II. A set of nullisomics define the germinal chromosomes Genetics 104: 257-270.

Carmell, M.A. and Hannon, G.J. 2004. RNase III enzymes and the initiation of gene silencing. Nat. Struct. Mol. Biol. 11: 214-218.

Cassidy-Hanley, D., Bowen, J., Lee, J.H., Cole, E., VerPlank, L.A., Gaertig, J., Gorovsky, M.A., and Bruns, P.J. 1997. Germline and somatic transformation of mating Tetrahymena thermophila by particle bombardment. Genetics 146: 135147.

Chalker, D.L. and Yao, M.C. 2001. Nongenic, bidirectional transcription precedes and may promote developmental DNA deletion in Tetrahymena thermophila. Genes \& Dev. 15: 1287-1298.

Cole, E.S., Cassidy-Hanley, D., Hemish, J., Tuan, J., and Bruns, P.J. 1997. A mutational analysis of conjugation in Tetrahymena thermophila. 1. Phenotypes affecting early development: Meiosis to nuclear selection. Dev. Biol. 189: 215-232.

Coyne, R.S., Chalker, D.L., and Yao, M.C. 1996. Genome downsizing during ciliate development: Nuclear division of labor through chromosome restructuring. Annu. Rev. Genet. 30: 557-578.

Coyne, R.S., Nikiforov, M.A., Smothers, J.F., Allis, C.D., and Yao, M.C. 1999. Parental expression of the chromodomain protein Pddlp is required for completion of programmed DNA elimination and nuclear differentiation. Mol. Cell 4: 865-872.

Fukagawa, T., Nogami, M., Yoshikawa, M., Ikeno, M., Okazaki, T., Takami, Y., Nakayama, T., and Oshimura, M. 2004. Dicer is essential for formation of the heterochromatin structure in vertebrate cells. Nat. Cell Biol. 6: 784-791.

Gorovsky, M.A. and Woodard, J. 1969. Studies on nuclear structure and function in Tetrahymena pyriformis J. Cell Biol. 42: 673-682.

Gorovsky, M.A., Yao, M.C., Keevert, J.B., and Pleger, G.L. 1975. Isolation of micro- and macronuclei of Tetrahymena pyriformis. Methods Cell Biol. 9: 311-327.

Hall, I.M., Shankaranarayana, G.D., Noma, K., Ayoub, N., Cohen, A., and Grewal, S.I. 2002. Establishment and maintenance of a heterochromatin domain. Science 297:22322237.

Hall, I.M., Noma, K., and Grewal, S.I. 2003. RNA interference machinery regulates chromosome dynamics during mitosis and meiosis in fission yeast. Proc. Natl. Acad. Sci. 100: 193198.

Huang, H., Wiley, E.A., Lending, C.R., and Allis, C.D. 1998. An HP1-like protein is missing from transcriptionally silent micronuclei of Tetrahymena. Proc. Natl. Acad. Sci. 95: 1362413629.
Jahn, C.L. and Klobutcher, L.A. 2002. Genome remodeling in ciliated protozoa. Annu. Rev. Microbiol. 56: 489-520.

Karrer, K.M. 2000. Tetrahymena genetics: Two nuclei are better than one. Methods Cell Biol. 62: 127-186.

Kirk, K.E., Harmon, B.P., Reichardt, I.K., Sedat, J.W., and Blackburn, E.H. 1997. Block in anaphase chromosome separation caused by a telomerase template mutation. Science 275: $1478-1481$.

Liu, Y., Mochizuki, K., and Gorovsky, M.A. 2004. Histone H3 lysine 9 methylation is required for DNA elimination in developing macronuclei in Tetrahymena. Proc. Natl. Acad. Sci. 101: 1679-1684.

Madireddi, M.T., Coyne, R.S., Smothers, J.F., Mickey, K.M., Yao, M.C., and Allis, C.D. 1996. Pdd1p, a novel chromodomain-containing protein, links heterochromatin assembly and DNA elimination in Tetrahymena. Cell 87: 75-84.

Makeyev, E.V. and Bamford, D.H. 2002. Cellular RNA-dependent RNA polymerase involved in posttranscriptional gene silencing has two distinct activity modes. Mol. Cell 10: 1417-1427.

Martindale, D.W., Allis, C.D., and Bruns, P.J. 1985. RNA and protein synthesis during meiotic prophase in Tetrahymena thermophila. J. Protozool. 32: 644-649.

Meister, G. and Tuschl, T. 2004. Mechanisms of gene silencing by double-stranded RNA. Nature 431: 343-349.

Mochizuki, K. and Gorovsky, M.A. 2004a. Conjugation-specific small RNAs in Tetrahymena have predicted properties of scan (scn) RNAs involved in genome rearrangement. Genes \& Dev. 18: 2068-2073.

. 2004b. Small RNAs in genome rearrangement in Tetrahymena. Curr. Opin. Genet. Dev. 14: 181-187.

- 2004c. RNA polymerase II localizes in Tetrahymena thermophila meiotic micronuclei when micronuclear transcription associated with genome rearrangement occurs. Eukaryotic Cell 3: 1233-1240.

Mochizuki, K., Fine, N.A., Fujisawa, T., and Gorovsky, M.A. 2002. Analysis of a piwi-related gene implicates small RNAs in genome rearrangement in Tetrahymena. Cell 110: 689699.

Morejohn, L.C., Bureau, T.E., Mole-Bajer, A.S., and Fosket, D.E. 1987. Oryzalin, a dinitroaniline herbicide, binds to plant tubulin and inhibits microtubule polymerization in vitro. Planta 172: 252-264.

Nikiforov, M.A., Smothers, J.F., Gorovsky, M.A., and Allis, C.D. 1999. Excision of micronuclear-specific DNA requires parental expression of Pdd2p and occurs independently from DNA replication in Tetrahymena thermophila. Genes \& Dev. 13: 2852-2862.

Nikiforov, M.A., Gorovsky, M.A., and Allis, C.D. 2000. A novel chromodomain protein, $\operatorname{Pdd} 3 p$, associates with internal eliminated sequences during macronuclear development in Tetrahymena thermophila. Mol. Cell Biol. 20: 4128-4134.

Pal-Bhadra, M., Leibovitch, B.A., Gandhi, S.G., Rao, M., Bhadra, U., Birchler, J.A., and Elgin, S.C. 2004. Heterochromatic silencing and HP1 localization in Drosophila are dependent on the RNAi machinery. Science 303: 669-672.

Prescott, D.M. 1994. The DNA of ciliated protozoa. Microbiol. Rev. 58: 233-267.

Provost, P., Silverstein, R.A., Dishart, D., Walfridsson, J., Djupedal, I., Kniola, B., Wright, A., Samuelsson, B., Radmark, O., and Ekwall, K. 2002. Dicer is required for chromosome segregation and gene silencing in fission yeast cells. Proc. Natl. Acad. Sci. 99: 16648-16653.

Reinhart, B.J. and Bartel, D.P. 2002. Small RNAs correspond to centromere heterochromatic repeats. Science 297: 1831.

Richards, E.J. and Elgin, S.C. 2002. Epigenetic codes for hetero- 
chromatin formation and silencing: Rounding up the usual suspects. Cell 108: 489-500.

Scherthan, H. 2001. A bouquet makes ends meet. Nat. Rev. Mol. Cell Biol. 2: 621-627.

Shang, Y., Song, X., Bowen, J., Corstanje, R., Gao, Y., Gaertig, J., and Gorovsky, M.A. 2002. A robust inducible-repressible promoter greatly facilitates gene knockouts, conditional expression, and overexpression of homologous and heterologous genes in Tetrahymena thermophila. Proc. Natl. Acad. Sci. 99: 3734-3739.

Smothers, J.F., Mizzen, C.A., Tubbert, M.M., Cook, R.G., and Allis, C.D. 1997. Pddlp associates with germline-restricted chromatin and a second novel anlagen-enriched protein in developmentally programmed DNA elimination structures. Development 124: 4537-4545.

Stargell, L.A. and Gorovsky, M.A. 1994. TATA-binding protein and nuclear differentiation in Tetrahymena thermophila. Mol. Cell Biol. 14: 723-734.

Stargell, L.A., Bowen, J., Dadd, C.A., Dedon, P.C., Davis, M., Cook, R.G., Allis, C.D., and Gorovsky, M.A. 1993. Temporal and spatial association of histone $\mathrm{H} 2 \mathrm{~A}$ variant hvl with transcriptionally competent chromatin during nuclear development in Tetrahymena thermophila. Genes \& Dev. 7: 26412651.

Strachan, S.D. and Hess, F.D. 1983. The biochemical mechanism of action of the dinitroaniline herbicide oryzalin. Pestic. Biochem. Physiol. 20: 141-150.

Strahl, B.D., Ohba, R., Cook, R.G., and Allis, C.D. 1999. Methylation of histone $\mathrm{H} 3$ at lysine 4 is highly conserved and correlates with transcriptionally active nuclei in Tetrahymena. Proc. Natl. Acad. Sci. 96: 14967-14972.

Sugai, T. and Hiwatashi, K. 1974. Cytologic and autoradiographic studies of the micronucleus at meiotic prophase in Tetrahymena pyriformis. J. Protozool. 21: 542-548.

Taverna, S.D., Coyne, R.S., and Allis, C.D. 2002. Methylation of histone h3 at lysine 9 targets programmed DNA elimination in tetrahymena. Cell 110: 701-711.

Volpe, T.A., Kidner, C., Hall, I.M., Teng, G., Grewal, S.I., and Martienssen, R.A. 2002. Regulation of heterochromatic silencing and histone H3 lysine-9 methylation by RNAi. Science 297: 1833-1837.

Volpe, T., Schramke, V., Hamilton, G.L., White, S.A., Teng, G., Martienssen, R.A., and Allshire, R.C. 2003. RNA interference is required for normal centromere function in fission yeast. Chromosome. Res. 11: 137-146.

Yao, M.C., Duharcourt, S., and Chalker, D.L. 2002. Genomewide rearrangements of DNA in ciliates. In Mobile DNA II (eds. N. Craig et al.), pp. 730-758. Academic Press, New York, NY.

Yao, M.C., Fuller, P., and Xi, X. 2003. Programmed DNA deletion as an RNA-guided system of genome defense. Science 300: $1581-1584$.

Zilberman, D., Cao, X., and Jacobsen, S.E. 2003. ARGONAUTE4 control of locus-specific siRNA accumulation and DNA and histone methylation. Science 299: 716-719. 


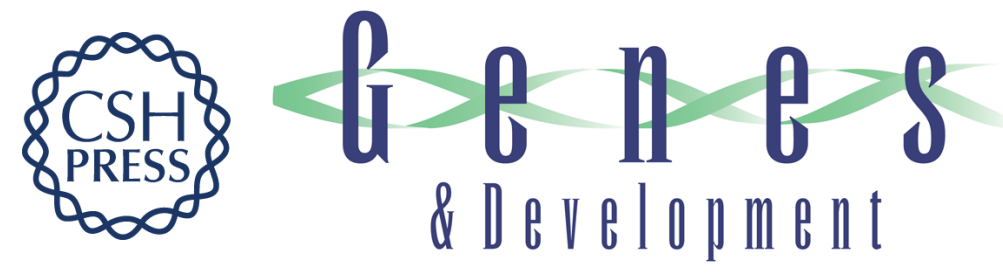

\section{A Dicer-like protein in Tetrahymena has distinct functions in genome rearrangement, chromosome segregation, and meiotic prophase}

Kazufumi Mochizuki and Martin A. Gorovsky

Genes Dev. 2005, 19:

Access the most recent version at doi:10.1101/gad.1265105

Supplemental
Material $\quad$ http://genesdev.cshlp.org/content/suppl/2004/12/15/gad.1265105.DC1

References This article cites 47 articles, 26 of which can be accessed free at:

http://genesdev.cshlp.org/content/19/1/77.full.html\#ref-list-1

License

Email Alerting Receive free email alerts when new articles cite this article - sign up in the box at the top

Service right corner of the article or click here.

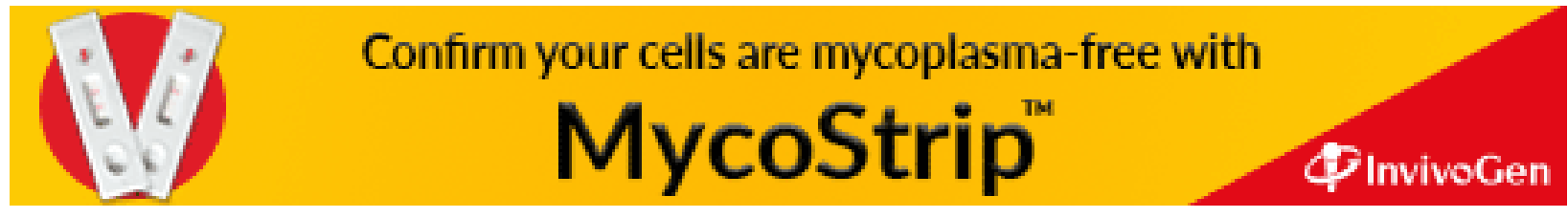

